\title{
Measurement and Analysis of China's Industrial Technical Efficiency
}

\author{
Bing Li \\ Jinan University, Guangzhou, China \\ Email: 18236583279@163.com
}

How to cite this paper: Li, B. (2018). Measurement and Analysis of China's Industrial Technical Efficiency. Journal of Financial Risk Management, 7, 109-122. https://doi.org/10.4236/jfrm.2018.71007

Received: February 5, 2018

Accepted: March 27, 2018

Published: March 30, 2018

Copyright (C) 2018 by author and Scientific Research Publishing Inc. This work is licensed under the Creative Commons Attribution International License (CC BY 4.0).

http://creativecommons.org/licenses/by/4.0/

\section{(c) (7) Open Access}

\begin{abstract}
This paper uses the stochastic frontier analysis to analyze the China's technical efficiency on the basis of 280 cities from 1998 to 2015. The empirical results indicated that: the average technical efficiency of China's industrial was increasing steadily in the past 18 years. The technical efficiency of east, middle and west regions are quite different: the east regions mean technical efficiency was higher than middle area about $27.3 \%$, or higher than west area about $35.9 \%$. In addition, the marketization process, $R \& D$ expenditure, education investment have a positive effect on the technical efficiency, but the FDI has a negative effect on eastern technical efficiency, which may due to the entry of FDI in eastern areas do not play a comparative advantage at the present stage.
\end{abstract}

\section{Keywords}

Stochastic Frontier Analysis, Technical Efficiency, Production Function

\section{Introduction}

The development of Chinese cities has changed dramatically since the reform and opening-up. Researchers at home and abroad pay great attention to the technical efficiency of China's industrial. Technical efficiency (TE) is linked with Production Frontier. Production frontier refers to the maximum output under a certain element input, different element inputs correspond to different outputs, and the curve of all outputs is the boundary of production frontier. Not all enterprises can achieve the maximum output. Under the equal input conditions, Technical efficiency of an enterprise is the distance between the output and the maximum output, the smaller the distance, the higher the technical efficiency.

There are two ways of measuring technical efficiency: parameter method and 
non-parametric method. Non-parametric method is proposed by Farrell and Afrait, then Variran and Fare et al. improved the theory. The method is to construct a minimum productive possibility set that contains the input and output of all the individuals in the sample: to obtain the maximum output with a certain input, or to obtain a certain output with minimal input. Non-parametric method has some advantages: With the non-parameter method, estimating the production function of the enterprises are not needed, and it can avoid the problems caused by the error production function. Non-parametric method has some disadvantages, it needs abundant individual data, has a high requirement for algorithm, and there is no description of the production process. The parameter method usually needs to estimate a production function at first, then it considers the compound structure and the distribution form of the error items, at last, according to the assumption of the distribution of the error items, it adopts the corresponding technical method to estimate per parameter in the production function. The parameter method can be used to describe the production process by estimating the production function.

The stochastic frontier model can avoid bring the exogenous noise error of industrial labor productivity into the endogenous technology inefficiency, and reduce the deviation between the measured technical efficiency and the real efficiency level. In this paper, we put a time variable into the production function and technology inefficiency function, in order to estimate the evolution trend of technology progress and technology efficiency of China's industry.

\section{Literature Review}

Researchers at home and abroad pay great attention to the technical efficiency of China's industrial. Some researchers, for example, He (2004) uses the SFA model to measure the average technical efficiency in the past 20 years of China's reform and opening-up. The empirical result indicates that the Chinese average technical efficiency was increasing steadily in the past two decades. The east-coast area's mean technical efficiency is higher than middle regions about fifteen percent or higher than west area about one-third. This research illustrates that the current situation of China's technological efficiency change, but does not make a thorough study in the factors that affect the technical efficiency.

Some researchers do some research on factors affecting technical efficiency, such as: pattern of ownership; FDI; institutional factors, R\&D expenditure and so on. Yao \& Zhang (2001) learn the factors that affect the technological efficiency of Chinese industrial firms: None state-owned enterprises are more efficient technologically than SOEs, while large enterprises are more efficient than peanuts; the spillover effect of FDI affects the technical efficiency through the flow of personnel, not the way of technology introduction. R \& D expenditure spent by provincial public research institutes has no effect on a firm's technological efficiency, but R \& D expenditure spent by firms significantly improves the technological efficiency of firms in a specific province; Regions also plays an 
important role in accounting for the difference in technological efficiency. Qu (2016) analysis the productivity differences and allocation effect from the two angles of the static and dynamic, The results about the static allocative efficiency shows that the labor productivity (MPL), compared with the capital productivity (MPK), has more balanced distribution, thus exhibiting better allocative status. For the dynamic aspect, the misallocation of the factor is mainly reflected in industries and ownerships. In three fields of industry, regions and ownership, the loss of labor misallotion is $1 \%$, and the loss of capital misallocation is $20 \%$. The flow of inter enterprises elements can improve the labor allocation by $13.6 \%$, and the allocation of capital can be improved by $628 \%$. Mac Dougall first proposed the spillover effect of FDI, and analyzed the impact of FDI on the host country's economy. After that, many researchers such as Kokko, Aitken and Harrison, Naihua Gu and Jiangfan Li, Lifang Huang, Liangwen Huang and Linlin Hong began to pay more attention to the spillover effect of FDI, They have developed it as an important branch of the FDI research field. Xia \& Cheng (2010), used Chinese data of industrial enterprises from 2000 to 2006 years, make a preliminary analysis of direct investment spillover effect on the technical efficiency of FDI, find that introduction of foreign capital has direct spillover effect, which increasing the enterprises technical efficiency by $6.28 \%$, but there is no indirect spillover effect; They also find that when the market share of foreign enterprises is kept at 55\%, the technology spillover effect of foreign enterprises is the best.

With a great deal of search and classification of the literature, it is found that there are obvious shortages of the study. First of all, there is no unified standard in evaluating whether the measurement of enterprises' technical efficiency is good or bad. Some researchers use total factor productivity instead of technical efficiency, which ignores the problem of "inefficiency" in the enterprises. Secondly, some researchers have conducted empirical researches on China's technical efficiency at the enterprises or the provincial level. For example, Qu (2014) calculates the technical efficiency, which using state-owned industrial enterprises data. Result shows that the technical efficiency of state-owned industrial enterprises decreases since 2000, the technical efficiency of non-state-owned enterprises is significantly higher than that of state owned enterprises. However, these studies based on enterprises samples are not enough for us to understand the technical efficiency of cities, let alone take a city as the unit, comparing the change of the technical efficiency between regions. Thirdly, some researchers observe only one factor, such as, the spillover effect of FDI on enterprises technical efficiency, they do not comprehensively analyze the impact of multiple variables on technological efficiency of enterprises, and do not deeply analyze the impact of marketization process on regional differences of technological efficiency of Chinese enterprises.

In order to analyze the efficiency changes of Chinese cities in recent years, this paper, applying stochastic frontier model (SFA), analyzes the technical efficiency 
evolution of 280 cities in China from 1998 to $2015^{1}$, decomposes the factors that affect the technical efficiency. The creation points of the thesis mainly embodies; 1) The SFA method can decompose residual into random perturbation item and technical inefficiency item. Then we can calculate the technical inefficiency of industrial enterprises accurately. 2) This paper makes a comprehensive comparison of the degree of influence of four factors, such as the degree of marketization, $R \& D$ expenditure, education expenditure, and FDI, on the technological efficiency of the enterprises. 3) We choose cities as economic units, and study the difference in technical efficiency of eastern and western cities.

\section{Theoretical Model}

The stochastic frontier analysis is proposed by Aigner et al., we use the stochastic frontier model to carry out empirical estimation, using over logarithmic Cobb-Douglas production function, to get the efficiency of capital allocation based on the micro foundation. The output function satisfies the following conditions:

$$
y_{i t}=f(x, t)+v_{i t}-u_{i t}, i=1, \cdots, N, t=1, \cdots T
$$

$y_{i t}$ represents the outputs of enterprises at $\mathrm{t}$ year. $x$ represents a set of element input vectors, $f(x, t)$ represents the deterministic frontier output in the stochastic frontier production function. $v_{i t}$ represents random interference item at time $t$, and $v_{i t} \sim N\left(0, \sigma_{v}^{2}\right), v_{i t}$ and $u_{i t}$ are independent of each other. $u_{i t}$ is a nonnegative random variable, which is assumed to estimate the technical inefficiency. Accroding to Battese \& Coelli (1992), $u_{i t}$ obeys an independent zero truncated normal distribution, $u_{i t} \sim N^{+}\left(m_{i t}, \sigma_{u}^{2}\right)$

$$
u_{i t}=u_{i} \varphi(t), \varphi(t)=\exp (-\eta(t-T))
$$

$\eta$ is the parameter to be estimated. when $\eta>0$, and $\varphi^{\prime}(t)<0, \varphi^{\prime \prime}(t)>0$, The technical efficiency of this part will be improved at an increasing rate. when $\eta<0$, and $\varphi^{\prime}(t)>0, \varphi^{\prime \prime}(t)<0$, The technical efficiency of this part will be improved at an decreasing rate. when $\eta=0$, There is no obvious change in the technical efficiency of this part.

In the form of transcendental logarithm, this paper uses the stochastic frontier analysis function model as follows:

$$
\ln y_{i t}=\beta_{0}+\beta_{k} \ln k_{i t}+\beta_{l} \ln k_{i t}+\beta_{t} t+\beta_{k t} t \ln k_{i t}+\beta_{l t} t \ln l_{i t}+v_{i t}-u_{i t}
$$

Judging whether the model is reasonable or not, we can see the proportion of the technology ineffective in the random perturbation term, that is $\gamma=\frac{\sigma_{u}^{2}}{\sigma_{u}^{2}+\sigma_{v}^{2}}(0 \leq \gamma \leq 1)$. When $\gamma$ is getting closer to 0 , the error of the

${ }^{1}$ In 2003-2013 years, China's prefectural cities changed. In 2011, the city of Chaohu was revoked, Xiangfan renamed Xiangyang, Bijie and Tongling were added. In 2013, the city of Simao was revoked, Puer and Haidong were added. In 2011 and 2012, there were 285 prefectural cities, but there were 284 prefectural cities in other years. Because some of the lack of sample data is not complete, and based on the requirements of SFA model for panel variables, Xiangyang, Beihai, Puer, Lincang and Karamay were deleted. Finally, 280 prefectural cities samples were identified. 
production function mainly comes from the noise error generated by the non-stochastic process. We should estimate the production function using the least square method (OLS). When $\gamma$ is getting closer to 1 , the error of frontier production function mainly comes from the technical ineffective terms. The influence of disturbance items is very small. It is suitable to estimate production function by stochastic frontier model.

\section{Empirical Results}

\subsection{Experimental Data Setup}

Based on the date we can be obtained, and in order to measure China's industrial technical efficiency, this paper selects 280 major cities in the country from 1998 to 2015, calculates the production function and technical efficiency, then analyzes the key factors that affect the technical efficiency. In January of 2017, Fang Gang market index 2016 published. This book evaluates the overall situation and progress of different aspects of the process of market reform in the provinces of China in 2008-2014. Due to the lack of data in 2015, this paper uses the 2014 market index to replace the 2015 data.

Table 1 shows the situation of Eastern, central and western cities. In this paper, 280 prefecture level cities are analyzed, including 114 eastern cities, 98 middle cities, and 67 western cities.

The total industrial output value, capital stock and employment (L), fixed asset investment (I) comes from the "The Annals of China City Statistical"; Fang Gang market index comes from the "Chinese provinces market index report", $\mathrm{R} \& \mathrm{D}$ expenditure, education expenditure and FDI data come from the WIND database. Based on the need for empirical. This paper disposes of R\&D expenditure, education expenditure and FDI by the GDP of the year.

In this paper, the panel data is used to analyze the total factor productivity in China, Production (Y) uses the total industrial output value calculated at the same year price in the regions; the capital stock $(\mathrm{k})$ is estimated by the perpetual inventory method: $K_{t}=K_{t-1}+I_{t}-\delta K_{t-1}$, and $K_{t}$ is the capital stock at t year, $I_{t}$ is the investment at $\mathrm{t}$ year, $\delta_{t}$ is the discount ratio at $\mathrm{t}$ year. The economic meaning of the upper type is: The capitals tock of the year was equal to the last year's net capital stock (the total capital stock minus the capital) plus the investment of the year. The capital stock of 1998 is $K_{1998}=I_{1998} /(g+\delta)$, $g=\ln \left(I_{2015} / I_{1998}\right) / 18, g$ is the average growth rate of 18 years of capital formation.

\subsection{Test of Stochastic Frontier Model}

Whether it can effectively measure the technical efficiency of the industrial enterprises in China has a great relationship with the correctness of the model. So, the validity and rationality of the stochastic frontier model needs to be tested and selected. This article is tested it using the method mentioned above, and the results are shown in Table 2. 
Table 1. The number of cities in East, West and central.

\begin{tabular}{ccc}
\hline No. & Regional & number \\
\hline 1 & East & 114 \\
2 & Central & 99 \\
3 & West & 67 \\
Total & & 280 \\
\hline
\end{tabular}

Table 2. Test results of random frontier model.

\begin{tabular}{ccc}
\hline & Estimated value & standard deviation \\
\hline$\gamma=\sigma_{u}^{2} /\left(\sigma_{u}^{2}+\sigma_{v}^{2}\right)$ & 0.6911493 & 0.0299681 \\
$\sigma_{u}^{2}$ & 0.3078897 & 0.0421829 \\
$\sigma_{v}^{2}$ & 0.1375853 & 0.0029027 \\
$\sigma^{2}=\sigma_{u}^{2}+\sigma_{v}^{2}$ & 0.445475 & 0.0420347 \\
Log likelihood & & -2603.4761 \\
\hline
\end{tabular}

The Table 2 illustrates the proportion of the technology ineffective in the random perturbation term, $\gamma=\frac{\sigma_{u}^{2}}{\sigma_{u}^{2}+\sigma_{v}^{2}}(0 \leq \gamma \leq 1)$. When $\gamma$ is getting closer to 0 , the error of the production function mainly comes from the noise error generated by the non-stochastic process. We should estimate the production function by the least square method (OLS). When $\gamma$ is getting closer to 1 , The error of frontier production function mainly comes from the technical ineffective term. The influence of disturbance items is very small. It is suitable to estimate production function by stochastic frontier model. Table 2 shows that $\gamma$ $=0.6911493, \gamma$ is closer to 1 , which indicates that more than $69.1 \%$ of the errors in the frontier production function are derived from technical inefficiencies. The rate of technology inefficiency is common in the industrial enterprises of various cities in China. Therefore, it is necessary to analyze the data at any time in the sample period.

\subsection{Model Estimation and Empirical Analysis}

\subsubsection{Empirical Results}

According to the formula (3), the maximum likelihood estimation method is used to estimate the random frontier model of the transcendental logarithm. The results are shown in Table 3 . The statistical value is positive at $1 \%$ significance level, and has passed the test of significance, The trend of technical efficiency is increasing progressively, This is a good evidence of our hypothesis: In the 18 years of 1998-2015 year, the technological efficiency of the basic urban industrial enterprises has been improved at an increasing rate in China.

From the regression coefficient of the above model. $\beta_{k}=0.4596621$, The stock of industrial capital increases at $1 \%$, which can increase the total industrial output value by 0.46 percentage points. $\beta_{l}=0.6789355$, It shows that the 
Table 3. Estimation of the production functions of 280 major cities in China: stochastic frontier analysis (1998-2015).

\begin{tabular}{|c|c|c|c|c|c|}
\hline \multirow{2}{*}{$\ln \left(y_{i t}\right)$} & \multirow{2}{*}{ Coefficient } & \multirow{2}{*}{ z-statistics } & \multirow{2}{*}{$\mathrm{P}>\mathrm{z}$} & \multicolumn{2}{|c|}{ Confidence interval 95\% } \\
\hline & & & & lower & upper \\
\hline $\ln \left(k_{i t}\right)$ & 0.4596621 & 17.07 & 0.000 & 0.406896 & 1.5124282 \\
\hline $\ln \left(l_{i t}\right)$ & 0.6789355 & 17.23 & 0.000 & 0.6016929 & 1.7561781 \\
\hline $\mathrm{T}$ & 0.1494304 & 6.82 & 0.000 & 0.1065127 & 1.1923481 \\
\hline$t \ln \left(k_{i t}\right)$ & 0.0025885 & 1.80 & 0.071 & -1.0002255 & 1.0054026 \\
\hline$t \ln \left(l_{i t}\right)$ & -0.025969 & -12.38 & 0.000 & -1.0300814 & -1.0218565 \\
\hline Cons & 5.928847 & 13.82 & 0.000 & 5.087774 & 6.76992 \\
\hline$\mu$ & 1.167196 & 11.94 & 0.000 & 1.9755765 & 1.358816 \\
\hline$\eta$ & 0.0093508 & 3.49 & 0.000 & 1.0041017 & 1.0146 \\
\hline $\ln \sigma^{2}$ & -0.8086141 & -8.57 & 0.000 & -1.993555 & -1.6236733 \\
\hline$I \lg t \gamma$ & 0.8054977 & 5.74 & 0.000 & 1.530337 & 1.080658 \\
\hline $\begin{array}{c}\text { Observation } \\
\text { number }\end{array}$ & 4877 & & $\begin{array}{l}\text { Number of } \\
\text { cities }\end{array}$ & 280 & \\
\hline Log Likelihood & -2603.4761 & & Wald $=6089.23$ & $\mathrm{p}$-value $=0.0000$ & \\
\hline
\end{tabular}

average annual increase of $1 \%$ of the labor force can promote the increase of industrial production by about 0.68 percentage points. The labor force increase at $1 \%$ annual, which can increase industrial production by about 0.68 percentage points. $\beta_{k}<\beta_{l}$, The contribution of the labor force to the total industrial output value is greater than the capital. The interaction between capital and time is positive, indicating that the contribution of capital to the total industrial output value is increasing. The interaction between labor and time is negative; It shows that as time goes on, the contribution of unit labor input to the total industrial output value is declining.

Taken together, the growth of the total industrial economy is still dominated by labor input. At present, China is still the factor driven economic development model, and the effect of labor force is more obvious. This is in line with the view of the mainstream. However, this paper finds that as time goes on, the contribution of the labor force to the total industrial output value is decreasing, while the contribution of the capital stock to the total industrial output value is increasing.

\subsubsection{Technical Efficiency of Production}

Based on the results of Table 3, let TE equal to exp $\left(-u_{i t}\right)$, we can calculate the technical efficiency values of each period of 280 cities in China, The result shows in Table 4.

In general, the average technical efficiency of industrial enterprises in China is not particularly high, which is between 0.71 and 0.75 , but presents a slow rising trend. From 1998 to 2015, the national technical efficiency rose from 0.72 to 0.75 , up 3 percentage points. Sub-regions, The level of technical efficiency in the 
Table 4. The national and regional technical efficiency in 1998-2015.

\begin{tabular}{|c|c|c|c|c|}
\hline Year & China & East & Central & West \\
\hline 1998 & 0.7223 & 0.82479 & 0.6394 & 0.61739 \\
\hline 1999 & 0.7212 & 0.82775 & 0.63887 & 0.61799 \\
\hline 2000 & 0.71543 & 0.82934 & 0.63977 & 0.61493 \\
\hline 2001 & 0.71659 & 0.83297 & 0.64383 & 0.61237 \\
\hline 2002 & 0.71153 & 0.82272 & 0.64683 & 0.6034 \\
\hline 2003 & 0.71167 & 0.82567 & 0.64733 & 0.6037 \\
\hline 2004 & 0.71411 & 0.82862 & 0.65035 & 0.60589 \\
\hline 2005 & 0.71622 & 0.83157 & 0.65338 & 0.60653 \\
\hline 2006 & 0.7192 & 0.83452 & 0.65642 & 0.60942 \\
\hline 2007 & 0.72218 & 0.83747 & 0.65947 & 0.61232 \\
\hline 2008 & 0.7254 & 0.84042 & 0.66188 & 0.6146 \\
\hline 2009 & 0.7286 & 0.84277 & 0.66604 & 0.61753 \\
\hline 2010 & 0.73116 & 0.84632 & 0.6687 & 0.62111 \\
\hline 2011 & 0.73416 & 0.84927 & 0.67179 & 0.62407 \\
\hline 2012 & 0.73718 & 0.85221 & 0.6749 & 0.62704 \\
\hline 2013 & 0.74019 & 0.85516 & 0.67801 & 0.63003 \\
\hline 2014 & 0.74228 & 0.85782 & 0.68113 & 0.63303 \\
\hline 2015 & 0.74637 & 0.86104 & 0.68427 & 0.63472 \\
\hline Average & 0.72532 & 0.83891 & 0.65902 & 0.617 \\
\hline
\end{tabular}

eastern regions was the highest, up to $86.10 \%$ in 2015 , which is obviously higher than the $63.47 \%$ in the western regions and the $68.42 \%$ in the central regions. The total technology efficiency in eastern China is $27 \%$ higher than that in the central regions, while the central regions is about $35 \%$ higher than that in the western regions. That is a striking demonstration that the economic development is positively related to the level of technical efficiency. From the average annual technical efficiency in China, we know that the efficiency of industrial production in the eastern regions is higher than the national average every year, while the national average industrial technology efficiency is higher than that in the central and western regions, the industrial technological efficiency gap between the East and the West has gradually increased. That is to say, the eastern regions maintain an absolute advantage and dominate the movement of the national industrial production frontiers. In the western regions, the number and quality of industrial enterprises are significantly lower than the Middle and East, and they are at the lowest level of the national industrial production frontiers.

\section{The Influence Factors of Technical Efficiency}

At present, the researchers do not have a unified theoretical framework to analy- 
sis the influence factors of technical efficiency. However, according to the research situation and observations of the economic facts, At least the following factors affect the technical efficiency of the 280 urban enterprises.

\subsection{The Degree of Marketization}

After the reform and opening up, the degree of China's marketization has been greatly improved.

The marketization can improve the technology efficiency of enterprises. On the one hand, Marketization brings competition, whether state-owned enterprises or private enterprises, will stimulate the enterprises to improve the production process. On the other hand, Marketization will standardize the link of enterprises purchasing, production and sale, reduce the transaction cost caused by information asymmetry, then improve the technical efficiency of the enterprises.

The development of China's eastern and western regions is out-of-balance. The eastern regions have two advantages over the Midwest in the process of marketization. At first, the eastern regions, which located on the coast, have a great convenient transportation. Second, Since 1980s, the central government carried uneven development strategies, the central investment was turned to the coastal regions, the enterprises in the East have gained a great advantage in the process of market-oriented reform. However, the geographical location and traffic in the central and western regions are at a disadvantage, and the development of the regions is also restricted by many bottlenecks. In this paper, we use Gang Fan and Xiaolu Wang's "China's Regional Marketization Process relative index" series research results as a proxy variable to measure the marketization level of 280 cities.

Table 5 is the changing trend of the marketization index of East, middle and Western China in the past 1998-2015 years. It is clear that there is a difference between the data before and after 2008. Because the situation has changed greatly after 2008, so the authors take 2008 as base period, recalculate and score the market data (Wang, Yu, \& Gang, 2016). We can still see the differences between the East, the middle and the West from the trend. As time goes on, the degree of marketization in China's eastern, central and western regions has been increasing, and the degree of marketization in the eastern regions is significantly higher than that in the central part, while the central part is also higher than that in the West. Besides, there is no shrinking trend in the marketization of the eastern and Western markets, but the gap between the central and Western markets is further expanding. Due to the high degree of marketization, the price signals can reflect the relationship between supply and demand timely. Prices can guide capital from inefficient industries to highly efficient industries, and optimize the efficiency of capital allocation (Wurgler, 2000). In addition, the development of marketization makes the product market, factor market, market intermediary organization and legal system environment more mature (Liu, 2012), so the 
Table 5. The changing trend of the marketization index in 1998-2015 years.

(a)

\begin{tabular}{cccccccccc}
\hline & 1998 & 1999 & 2000 & 2001 & 2002 & 2003 & 2004 & 2005 & 2006 \\
\hline East & 5.22 & 5.01 & 5.51 & 6.34 & 6.79 & 7.25 & 7.81 & 8.37 & 8.85 \\
West & 3.01 & 3.21 & 3.15 & 3.23 & 3.51 & 3.99 & 4.55 & 5.12 & 5.47 \\
Mid & 4.27 & 3.93 & 3.99 & 4.03 & 4.44 & 4.95 & 5.66 & 6.33 & 6.68 \\
East/West & 1.74 & 1.56 & 1.75 & 1.96 & 1.94 & 1.81 & 1.72 & 1.63 & 1.62 \\
East/Mid & 1.22 & 1.27 & 1.38 & 1.57 & 1.53 & 1.46 & 1.38 & 1.32 & 1.33 \\
Mid/West & 1.42 & 1.23 & 1.26 & 1.25 & 1.27 & 1.24 & 1.24 & 1.24 & 1.22 \\
\hline
\end{tabular}

(b)

\begin{tabular}{cccccccccc}
\hline & 2007 & 2008 & 2009 & 2010 & 2011 & 2012 & 2013 & 2014 & 2015 \\
\hline East & 9.27 & 6.71 & 6.84 & 6.88 & 7.09 & 7.67 & 7.86 & 8.2 & 8.2 \\
West & 5.88 & 4.18 & 4.14 & 3.84 & 3.91 & 4.15 & 4.29 & 4.69 & 4.69 \\
Mid & 7.06 & 5.43 & 5.47 & 5.51 & 5.71 & 5.96 & 6.16 & 6.65 & 6.65 \\
East/West & 1.58 & 1.61 & 1.65 & 1.79 & 1.81 & 1.85 & 1.83 & 1.75 & 1.75 \\
East/Mid & 1.31 & 1.24 & 1.25 & 1.25 & 1.24 & 1.29 & 1.28 & 1.23 & 1.23 \\
Mid/West & 1.2 & 1.3 & 1.32 & 1.43 & 1.46 & 1.43 & 1.43 & 1.42 & 1.42 \\
\hline
\end{tabular}

Data source: Fang Gang, Xiaolu Wang "China provincial market index report" (1998-2016); Notes: There is a difference between the data before and after 2008. Because the situation has changed greatly after 2008, so the authors take 2008 as base period, recalculate and score the market data (Wang, Yu, \& Gang, 2016).

eastern regions' industrial development is better than that of the central and western regions. Therefore, this paper holds the view that the degree of marketization is an important reason for the difference in the technological efficiency of the enterprises.

\subsection{R\&D Expenditure}

To a large extent, the size of R\&D expenditure determines the technological level and technological innovation capability of enterprises, which will inevitably exert great influence on the technological efficiency of enterprises (Yao \& Zhang, 2001). The decline of R\&D's investment growth rate is an important reason for the slow growth of China's economic efficiency (Li \& Li, 2008). Shi (2011) finds that the impact of R\&D spending on Eastern, central and western technological efficiency is significantly different, and shows a decreasing trend in eastern, Western and central regions. In terms of R\&D expenditure, public research institutions, large and medium-sized state-owned enterprises play a leading role, and these institutions have also become the main body of China's technology supply. In terms of technology acquisition, large enterprises tend to independent research and development, while small and medium-sized enterprises tend to buy off-the-shelf technology directly. The subject of this paper is the enterprises above the scale, so the R\&D expenditure is very likely to have a strong impetus to the improvement of technical efficiency. 


\subsection{Education Expenditure}

Human capital is the source of economic growth, and education is an important way to form human capital, and it is the basis for scientific development and nurturing talents (Schultz, 1982). Lucas (1988) also pointed out that after receiving education, Workers' productivity and income will be improved, and the productivity of the surrounding people and even the whole society's productivity will be improved. The impact of education on productivity is mainly reflected in two aspects: First, education is the foundation of technology development and knowledge economy, directly restricts the efficiency level, productivity growth and technological progress of resource allocation in all areas of the economy. The two is that education has a typical external spillover effect on technical efficiency and technological progress. Once people with a good level of education get the technology, they can improve the efficiency of technology application and obtain higher productivity and technical level. When studying the human capital, the most widely used method is the education stock method, that is, giving the educational background the corresponding weights, and the average educational level of laborers is multiplied by the educated years and the corresponding weights. This paper holds that there is a significant positive correlation between the input and output of education, and the data using educational expenditure can be used to measure the overall quality of the workers accurately.

\subsection{FDI}

There are disputes among researchers on whether FDI has improved the technical efficiency of industrial enterprises. Some researchers believe that FDI can significantly improve the economic efficiency of China and the total factor productivity: Liu et al. (2008) investigates the spillover effect of FDI on domestic enterprises, and find that foreign capital can improve the total factor productivity of enterprises in the surrounding areas, but has little effect on far away enterprises. Huang et al. (2007) find that the technology level of host country has a significant role in promoting FDI technology spillover, which reflects the importance of FDI capacity in a country or regions. Other researchers hold a reservation on whether FDI has improved its economic efficiency. Yao \& Zhang (2001) analyse FDI in both qualitative and quantitative ways and find that the entry of FDI has little role in the dissemination of advanced technology. Wang (1997) believes that the main purpose of foreign capital is to occupy the domestic market, or just to make use of cheap labor force in China, rather than to produce advanced international products. Therefore, FDI will not play a great role in improving the technological efficiency of enterprises.

In view of the uncertainty of the existing literature, this paper brings FDI into one of the explanatory variables that affect the technical efficiency.

There are four factors affecting the technical efficiency: the degree of marketization, $R \& D$ expenditure, education expenditure, FDI. In this paper, we have a regression analysis between technical efficiency and four influencing factors. The regression results are shown in Table 6. From the nationwide angle, there is a 
significant positive correlation between technical efficiency and the degree of marketization, R\&D expenditure and educational expenditure, which indicated the improvement of the market level, the increase of $R \& D$ expenditure and the increase of educational expenditure can improve the level of the national technical efficiency. Specially, the impact of educational expenditure on technical efficiency is most obvious. However, the correlation between FDI and technology efficiency is not consistent with expectations, and the correlation coefficient is only -0.0003655 , indicating that foreign investment has not played a positive role in China's industrial technology efficiency. The empirical results in the East are in agreement with the national empirical results. This is consistent with the conclusions of Wang (1997), the possible reason is: The eastern regions has a high degree of marketization and a large investment in education and research. FDI investment does not help the eastern industrial enterprises to import advanced technology, so FDI plays a little role in improving the efficiency of enterprises in the eastern regions, while the technical efficiency of the country is more obviously influenced by the East.

From the empirical results of the central and western regions. The technical efficiency has a positive correlation with the degree of marketization, R\&D expenditure, education expenditure and FDI, the effect of education expenditure on technical efficiency is the most obvious. FDI increases can increase the technical efficiency level of the regions. The possible reason is: The degree of marketization in the central and western regions is relatively low. The entry of FDI brings a great deal of applicable technologies linking with the current national conditions, and is more conducive for the enterprises to take advantage of the comparative advantages at this stage.

\section{Conclusion}

This paper uses the stochastic frontier analysis to analyze the China's technical efficiency on the basis of 280 cities since 1998 to 2015. The empirical results

Table 6. The influence factors of technical efficiency.

\begin{tabular}{|c|c|c|c|c|c|c|c|c|}
\hline \multirow{2}{*}{$\mathrm{Te}$} & \multicolumn{2}{|c|}{ China } & \multicolumn{2}{|c|}{ East } & \multicolumn{2}{|c|}{ Mid } & \multicolumn{2}{|c|}{ West } \\
\hline & Coefficient & $\mathrm{P}>\mathrm{z}$ & Coefficient & $\mathrm{P}>\mathrm{z}$ & Coefficient & $\mathrm{P}>\mathrm{z}$ & Coefficient & $\mathrm{P}>\mathrm{z}$ \\
\hline $\mathrm{R} \& \mathrm{D}$ & 0.0065808 & 0.000 & 0.0083072 & 0.000 & 0.0063117 & 0.000 & 0.0044212 & 0.000 \\
\hline EDU & 0.0084352 & 0.000 & 0.011869 & 0.000 & 0.0083953 & 0.000 & 0.0056474 & 0.000 \\
\hline FDI & -0.0003996 & 0.003 & -0.0003655 & 0.030 & 0.0003986 & 0.337 & 0.0003703 & 0.454 \\
\hline _cons & 0.2823411 & 0.000 & 0.4048874 & 0.000 & 0.2209787 & 0.000 & 0.170251 & 0.000 \\
\hline$\sigma_{u}$ & 0.11749788 & & 0.13739913 & & 0.05556658 & & 0.07744142 & \\
\hline$\sigma_{e}$ & 0.00875985 & & 0.00762595 & & 0.00967296 & & 0.00793982 & \\
\hline
\end{tabular}


indicated that: the average technical efficiency of China's industrial was increasing steadily in the past 18 years. Besides, we find that the technical efficiency of east, middle and west regions are quite different: the east regions mean technical efficiency was higher than middle area about $27.3 \%$, or higher than west area about $35.9 \%$. That fully shows that the degree of economic development is positively related to the technical efficiency. In addition, this paper also analyzes the factors that influence the technical efficiency. The research shows that the degree of marketization, $\mathrm{R} \& \mathrm{D}$ expenditure and education level are positively correlated with technical efficiency, and the impact of education level on technological efficiency is the most obvious, while FDI is negatively correlated with technical efficiency.

In view of the above conclusions, in order to promote the development of China's urban industry, we have the following policy implications: First, we should increase the investment in education or introduce advanced talents, improve technical efficiency and increase the level of industry. Second, we should accelerate the market reform, improve the industrial market environment, and promote the good and rapid development of industry. Third, we should increase R\&D expenditure, import advanced science and technology and equipment, increase actual industrial output value, and narrow the gap between expected industrial output values.

\section{Notes}

In this paper, the East includes: Beijing, Tianjin, Hebei, Liaoning, Shanghai, Jiangsu, Zhejiang, Fujian, Shandong, Guangdong, Guangxi, Hainan.

The central part includes Shanxi, Jilin, Heilongjiang, Anhui, Jiangxi, Henan, Hubei and Hunan.

The West includes Chongqing, Sichuan, Yunnan, Guizhou, Shaanxi, Gansu, Qinghai, Xinjiang, Ningxia, Inner Mongolia, Tibet.

\section{References}

Battese, G. E., \& Coelli, T. J. (1992). Frontier Production Functions, Technical Efficiency and Panel Data: With Application to Paddy Farmers in India. Journal of Productivity Analysis, 3, 153-169. https://doi.org/10.1007/BF00158774

He, F. (2004). The Measurement of Chinese Technical Efficiency: The Application of Stochastic Frontier Production Function. Science Research Management, No. 05, 46-50.

Huang, L. Y., Fan, Y. X., \& Liu, X. M. (2007). Technology Spillovers of FDI Based on Host's Absorptive Capacity, An Emperical Analysis. China Soft Science, No. 3, 30-34.

Li, S. W., \& Li, D. S. (2008). China's Industrial Total Factor Productivity Fluctuations: 1986-2005. Journal of Quantitative \& Technical Economics, 25, 43-54.

Liu, C., Shi, Q., \& Liu, Y. F. (2012). An Empirical Study of Regional Disparity of China's Industrial Technical Efficiency. Journal of Tianjin University of Commerce, 32, 42-48.

Liu, S. Y., Lu, J. Y., \& Tao, Z. G. (2008). Spillovers of FDI on Indigenous Manufacturing Firms: A Perspective of Geographic Distance. China Economic Quarterly, 8, 115-128. 
Lucas, R. E. Jr. (1988). On the Mechanics of Economic Development. Journal of Monetary Economics, 22, 3-42. https://doi.org/10.1016/0304-3932(88)90168-7

Qu, Y. (2016). The Productivity Differences and the Losses of Allocative Efficiency of China's Industries, World Economic, 39, 121-142.

Qu, Z. (2014). Efficiency of State-Owned Industrial Enterprise in China. Journal of Industrial Technological Economics, 1, 42-50.

Schultz (1982). CH.3: The Economic Value of Education. In The Economic Value of Education (pp. 60-96). Changchun: Jilin Publishing Group Co., Ltd.

Shi, P. (2011). The Analysis of Total Factor Productivity Growth Features and Spatial Differences of China's R\&D Innovation. Science of Science and Management of s\&t, 32, 35-39.

Wang, X. L., Yu, J., \& Gang, F. (2016). Marketization Index of China's Province. Beijing: Social Science Academic Press.

Wang, Y. P. (1997). An Empirical Analysis of Foreign Direct Investment and the Development of China's Industry. Beijing: Internal Discussion of the China Economic Research Center of Peking University.

Wurgler, J. (2000). Financial Markets and the Allocation of Capital, Journal of Financial Economics, 58, 187-214. https://doi.org/10.1016/S0304-405X(00)00070-2

Xia, C. L., \& Cheng, L. (2001). Research on the Spillover Effects of FDI on the Technical Efficiency of China's Industrial Enterprises-The Quantitative Analysis of Chinese Industrial Firms from 2002 to 2006. China Industrial Economics, No. 07, 55-65.

Yao, Y., \& Zhang, Q. (2001). An Analysis of Technological Efficiency of Chinese Industrial Firm. Economic Research, No. 10, 13-19+28-95. 